\title{
Treatment with Lingqi capsules suppresses colorectal cancer by inhibiting the hepatocyte growth factor/c-Met signal transduction pathway
}

\author{
GUO-SHENG WANG ${ }^{1}$, JIN-LONG ZHAO ${ }^{1}$ and HUAN LI ${ }^{2}$ \\ ${ }^{1}$ Department of Colorectal Surgery, The First Affiliated Hospital of Harbin Medical University, Harbin, Heilongjiang 150001; \\ ${ }^{2}$ Department of Pharmacy, School of Medicine, Shenzhen University, Shenzhen, Guangdong 518060, P.R. China
}

Received January 17, 2014; Accepted September 12, 2014

DOI: $10.3892 / \mathrm{mmr} .2014 .2887$

\begin{abstract}
Lingqi capsules (LQCs) are commonly used in Chinese herbal medicine to support the immune system and inhibit tumor growth. The capsules are considered to have a direct effect on tumor cell proliferation and support tumor cell apoptosis. In the present study, the effects of LQC serum on the colorectal cancer cell line, LoVo, and on tumors induced by the cell line were investigated in nude mice. LQC serum was generated by feeding Wistar rats LQC and isolating the serum from blood samples obtained from the rats. The serum was then used to treat LoVo cells for 24,48 and $72 \mathrm{~h}$, after which the cell morphology and proliferation were assessed. In addition, nude mice were injected with $0.2 \mathrm{ml}$ LoVo cells subcutaneously to produce tumors. After $24 \mathrm{~h}$, xenografted nude mice were treated with $5.0,2.5$ or $1.25 \mathrm{~g} / \mathrm{kg} /$ day LQC serum by gavage for 21 days and the tumor growth, morphology, apoptosis of tumor cells and expression profiles of hepatocyte growth factor (HGF) and its receptor, c-Met, were investigated. Compared with the negative controls, inhibition of cell growth was clearly visible in the LoVo cells treated for 24, 48 and $72 \mathrm{~h}$ and this inhibition was enhanced as the exposure time and drug concentration increased. The growth of solid tumors induced by the transplantation of LoVo cells into nude mice was inhibited to differing degrees. Following LQC treatment, the apoptotic rates of the cells were increased, the protein and mRNA expression levels of HGF were downregulated and those of c-Met were upregulated. These findings suggest that LQC treatment inhibits colorectal cancer by downregulating the HGF/c-Met signal transduction pathway.
\end{abstract}

Correspondence to: Dr Huan Li, Department of Pharmacy, School of Medicine, Shenzhen University, 3688 Nanhai Avenue, Shenzhen, Guangdong 518060, P.R. China

E-mail: lihuan1106@126.com

Key words: Lingqi capsule, hepatocyte growth factor/c-Met, signal transduction pathway, colorectal cancer

\section{Introduction}

The incidence of colorectal cancer has risen steadily and currently ranks among the top three types of cancers affecting males and females in Europe (1). As of 2004, in China, the mortality rate of colorectal cancer was 5.29/100,000 in males and 3.86/100,000 in females, placing it among the sixth most life-threatening types of cancer affecting the Chinese population (2). Currently, a combination of surgery, radiotherapy and chemotherapy is used to treat colorectal cancer (3).

There is increasing evidence that Chinese herbal medicine may assist in treating certain types of cancer. Herbal medicine has been found to inhibit the growth of tumor cells, improve disease symptoms and reduce the side-effects of radiotherapy and chemotherapy. Studies of antitumor herbal medicine have revealed a variety of effects on cells, including the inhibition of tumor cell proliferation, promotion of apoptosis and alterations in the expression of tumor-associated genes. Lingqi capsules (LQC), which include Ganoderma lucidum, Astragalus membranaceus, ginseng and Pseudobulbus Cremastrae seu Pleiones are a compound preparation, which are intended to tonify qi, nourish yin, eliminate pathogens, detoxify and disperse masses (4-5). Treatment with LQC has been shown to inhibit the proliferation and growth of lung adenocarcinoma cells and tumor metastasis (6-8). Furthermore, the pathogenetic mechanism of tumors is that the number of apoptotic cells is insufficient to control the excessive proliferation of abnormal cells $(9,10)$. In the present study, the colorectal cancer cell line, LoVo, was used to investigate the effect and mechanism of LQC on tumor growth in vitro and in vivo in an animal model.

\section{Materials and methods}

Materials. LQCs were produced by the Drug Manufacturing Room of the First Affiliated Hospital of Harbin Medical University (Harbin, China). Each capsule contained $0.4 \mathrm{~g}$ Astragalus membranaceus, 0. 3g Ganoderma lucidum, 0.2 g Curcuma zedoaria, 0.2 g Poria cocos, 0.15 g ginseng, $0.15 \mathrm{~g}$ Cyrtomium fortune, $0.1 \mathrm{~g}$ Chinese yam, $0.05 \mathrm{~g}$ fruit of the Chinese wolfberry, $0.05 \mathrm{~g}$ Paris polyphylla and $0.05 \mathrm{~g}$ Pseudobulbus Cremastrae seu Pleiones, dissolved in saline. The Wistar rats and nude mice were provided by the Drug Safety 
Evaluation Center of Heilongjiang University of Traditional Chinese Medicine (Heilongjiang, China). The LoVo colorectal cancer cells were provided by the Provincial Cancer Institute of Heilongjiang (Heilongjiang, China).

\section{Materials and methods}

Preparation of $L Q C$ serum. Animal welfare and experimental procedures were performed in strict accordance with animal welfare and other related ethical regulations, and approved by the Institutional Animal Care Committee of Drug Safety Evaluation Center at Heilongjiang University of Chinese Medicine (Harbin, China). Wistar rats were randomly divided into five groups with four individuals in each: the low-, mediumand high-dose LQC groups, the negative control group and the positive control group, treated with cyclophosphamide tablets (Haizheng Pharmaceutical Co., Taizhou, China). The rats in the low-, medium- and high-dose LQC groups were gavaged with $8.91,17.82$ and $35.64 \mathrm{~g} / \mathrm{kg}$ /day LQC, respectively. The rats in the negative control group received saline. Animals in the positive control group received $0.027 \mathrm{~g} / \mathrm{kg} /$ day cyclophosphamide. The rats were gavaged continuously for 7 days and blood samples were obtained from the inferior vena cava $2 \mathrm{~h}$ after the final gavage. The LQC serum was separated using $0.22-\mu \mathrm{m}$ microporous filter sterilization and the processed samples were stored in a refrigerator at $-20^{\circ} \mathrm{C}$.

LQC treatment of cultured cells. The LoVo cells were trypsinized and counted during the logarithmic growth phase. Subsequently, $1 \times 10^{5}$ cells $/ \mathrm{ml}$ were inoculated on a 6 -well plate and cultured overnight in $7.5 \% \mathrm{CO}_{2}$. Following cell adherence, $50 \mu 1$ serum containing low-, medium- or high-dose LQC was added to the cells. The positive control group received serum from the rats treated with cyclophosphamide and the negative control group received serum from rats treated with an equal volume of saline. The cells were then incubated for 24,48 and $72 \mathrm{~h}$, at $37^{\circ} \mathrm{C}$ in $5 \% \mathrm{CO}_{2}$. The cell morphology and the quantity, color and transparency of the culture medium, as well as adhesion, adherence, stretching, moving and other activities of the cells were observed under an inverted microscope (Olympus CKX31; Olympus Corporation, Tokyo, Japan).

Detection of LoVo cell proliferation by MTT assay. Cells in the logarithmic growth phase were collected and inoculated into a 96-well plate (100 $\mu 1$ of $1 \times 10^{5}$ cells/well) and were then cultured overnight in an incubator at $37^{\circ} \mathrm{C}$ and $5 \% \mathrm{CO}_{2}$ (volume fraction). RPMI-1640 (50 $\mu \mathrm{l}$ ) was added to each well, while serum from the rats treated with cyclophosphamide tablets was added to the positive control group and an equal volume of serum from the saline-treated rats was added to the negative control group. Each group had six parallel wells. The cells were cultured for 24,48 and $72 \mathrm{~h}$, at $37^{\circ} \mathrm{C}$ in $5 \%$ $\mathrm{CO}_{2}$, following addition of the serum. MTT $(20 \mu \mathrm{l} ; 5 \mathrm{mg} / \mathrm{ml})$ was then added to each well and the medium was discarded after $4 \mathrm{~h}$. Dimethyl sulfoxide (150 $\mu \mathrm{l})$ was added to each well to terminate the reaction and decoloration and agitation were applied for $10 \mathrm{~min}$. Optical absorbance was determined at $490 \mathrm{~nm}$ using a microplate reader (450 SN11693; Bio-Rad, Hercules, CA, USA) and the rate of cell growth inhibition (\%) was calculated using the following formula: 1 - (absorbance value of the experimental group / absorbance value of the negative control group) $\mathrm{x} 100$.

Tumor modeling in nude mice. The nude mice were randomly divided into five groups: low-, medium- and high-dose LQC groups $(1.25,2.5$ and $5.0 \mathrm{~g} / \mathrm{kg}$, respectively), a negative control group ( $0.2 \mathrm{ml}$ normal saline) and a positive control group (39 $\mathrm{mg} / \mathrm{kg}$ cyclophosphamide), with four mice in each group. The nude mice were subcutaneously inoculated in the armpit of the right front limb with $0.2 \mathrm{ml} \mathrm{LoVo} \mathrm{cells} \mathrm{following} \mathrm{routine}$ skin disinfection. Treatment began $24 \mathrm{~h}$ after inoculation and the mice in the five groups were gavaged continuously for 21 days. The mice were sacrificed through orbital venous blood drawing on the second day following drug administration (day 22). The skin from the surgical sites was then sterilized using alcohol and stripped of tumor nodules. Fibrous and necrotic tissue was then removed and weighed on an analytical balance.

Detection of apoptosis in the tumor-bearing mice. The tumor tissues were cut on an ice tray using ophthalmic scissors, placed on a 300-mesh copper grid, washed with phosphate-buffered saline (PBS) solution and prepared as a single cell suspension by rubbing the grid. The precipitate was removed and the concentration of the cells was adjusted to $2 \times 10^{6}$ cells $/ \mathrm{ml}$. A $1-\mathrm{ml}$ sample of the cell suspension was added to $1.6 \mathrm{ml} \mathrm{RNase}(1 \mathrm{mg} / \mathrm{ml})$ and incubated at $37^{\circ} \mathrm{C}$ in a water bath for $30 \mathrm{~min}$. Following centrifugation AT $2,3000 \mathrm{xg}$ for $10 \mathrm{~min}$, the precipitate was dissolved in $0.4 \mathrm{ml}$ PBS. Subsequently, $200 \mu 1$ propidium iodide (PI; Sigma, St. Louis, MO, USA) dye containing $200 \mathrm{mg} / \mathrm{ml} \mathrm{PI,} 1 \%$ Triton, $0.9 \% \mathrm{NaCl}$ and $50 \mathrm{mg} / \mathrm{ml} \mathrm{RNase}$ ) were added at $4^{\circ} \mathrm{C}$ and the cells were stained for $30 \mathrm{~min}$. Detection was performed using flow cytometry at $488 \mathrm{~nm}$ excitation (BD FACSAria III, BD Biosciences, Franklin Lakes, NJ, USA). The number of PI-positive cells was automatically determined using computer software (CellQuest, BD Biosciences). A DNA content distribution diagram was generated to determine the apoptotic rate.

Detection of the protein expression of $H G F$ and c-Met by western blotting. Tumor tissue blocks $(10 \mathrm{mg})$ were placed in a homogenizer (Bio-Gen PRO200, PRO Scientific, Oxford, CT, USA)and cut into small pieces using clean tissue scissors. Single detergent lysates $(400 \mu 1 ; 50 \mathrm{mM}$ Tris (pH 7.4), $150 \mathrm{mM} \mathrm{NaCl}$, $1 \%$ NP-40, $0.5 \%$ sodium deoxycholate) were added for homogenization and the homogenizer was placed on ice to repeatedly grind the tissue. After $30 \mathrm{~min}$, the lysate was transferred to 1.5 - $\mathrm{ml}$ Eppendorf tubes and centrifuged at $12,000 \mathrm{rpm}$ at $4^{\circ} \mathrm{C}$ for $5 \mathrm{~min}$. The supernatant was collected by centrifugation at $13,400 \mathrm{x} \mathrm{g}$, and sub-packaged in $0.5-\mathrm{ml}$ tubes stored at $-20^{\circ} \mathrm{C}$. $\beta$-actin (anti- $\beta$-actin antibody, Santa Cruz Biotechnology, Inc., Santa Cruz, CA, USA) was used as the internal reference. The proteins were separated by 5\% SDS-PAGE and then electrophoretically transferred onto polyvinylidene difluoride (PVDF) membranes (Pall Corporation, Port Washington, NY, USA). The PVDF membrane was sealed using confining liquid [5\% skim milk and TBST $\left(20 \mathrm{mM}\right.$ Tris- $\mathrm{HCl}, \mathrm{pH} 7.4\left(25^{\circ} \mathrm{C}\right)$, $150 \mathrm{mM} \mathrm{NaCl}$ and $0.05 \%$ Tween $\left.^{\circledR}-20\right)$ ] for $1 \mathrm{~h}$ and mouse anti-human monoclonal antibodies against HGF or c-Met were added (1:100; Sigma) prior to the membrane being placed on 


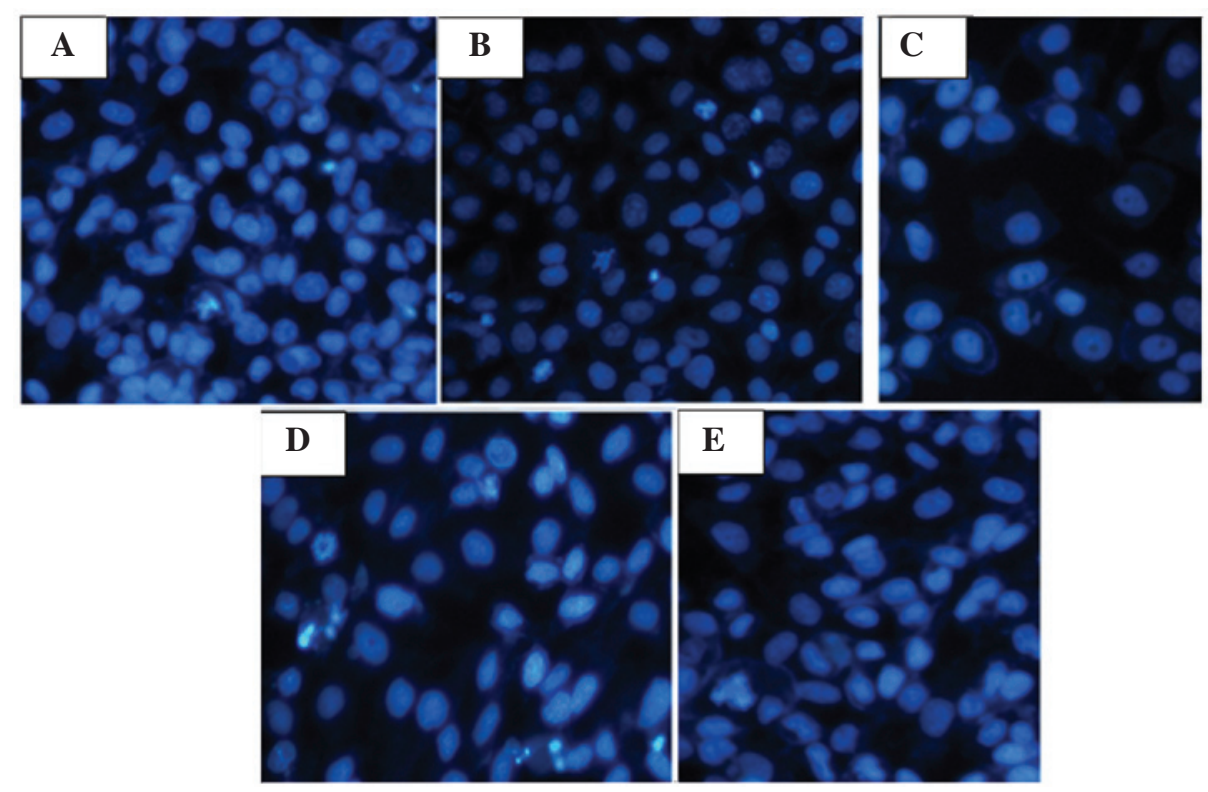

Figure 1. Observation of LoVo cell morphology within the different treatment groups. The cells were stained with Hoechst 33258, and observed under an inverted microscope (Olympus CKX31; magnification, x400). (A) Low-dose LQC (1.25 g/kg). (B) Medium-dose LQC (2.5 g/kg). (C) High-dose LQC (5.0 g/ $\mathrm{kg}$ ). (D) Positive control (39 mg/kg cyclophosphamide) and (E) negative control (0.2 $\mathrm{ml}$ normal saline). LQC, Lingqi capsules.

an agitator overnight at $4^{\circ} \mathrm{C}$. Horseradish peroxidase-labeled goat anti-mouse immunoglobulin $\mathrm{G}$ polyclonal antibody was used as the secondary antibody (1:1,000; Sigma), which was added prior to incubation of the membrane at $37^{\circ} \mathrm{C}$ for $2 \mathrm{~h}$. Following washing with Tris-buffered saline with Tween, chemiluminescence agent (Thermo SuperSingle West Femto Trial kit; Thermo Fisher Scientific, Waltham, MA, USA) was added and the protein expression levels were determined by electrochemiluminescence detection. Image-Pro Plus software (Media Cybernetics, Inc., Bethesda, MD, USA) was used to calculate the average gray values of the HGF and c-Met proteins relative to that of $\beta$-actin.

Detection of the MRNA expression of HGF and c-Met by reverse transcription quantitative polymerase chain reaction $(R T-q P C R)$. Liquid nitrogen and a mortar were used to grind $1.0 \mathrm{~g}$ tumor tissue for RNA extraction using TRIzol reagent (Invitrogen Life Technologies, Carlsbad, CA, USA). A spectrophotometer (Solid Spec-3700DUV; Shimadzu Corporation, Kyoto, Japan)was then used to detect the concentration of total RNA. Based on the published sequences in GenBank, the following primers were used: $H G F$, forward 5'-AATGCAGCCAGCATCCATCG-3' and reverse 5'-CCACCATTATCCCCCTCACAT-3' and $c$-MET, forward 5'-ACCTCAGCAA TGTCAGCACCA-3' and reverse 5'-GGCCATGTGATGTCATTCTGG-3'. RT-qPCR was performed using PrimeScript RT kits and the RT-qPCR reaction liquid was prepared according to the manufacturer's instructions (Takara Bio, Inc., Shiga, Japan). The RT-qPCR reaction conditions were as follows: RT at $37^{\circ} \mathrm{C}$ for $15 \mathrm{~min}$ and $85^{\circ} \mathrm{C}$ for $15 \mathrm{sec}$. The cDNA samples were obtained and the template replaced with sterile deionized water as a negative control. The qPCR reaction liquid was prepared on ice according to the SYBR Premix Ex Taq kit instructions (Takara Bio, Inc.). The qPCR reaction was performed as follows: denaturing at $95^{\circ} \mathrm{C}$ for $10 \mathrm{sec}, 9^{\circ} \mathrm{C}$ for $5 \mathrm{sec}, 60^{\circ} \mathrm{C}$ for $34 \mathrm{sec}$ and amplifying to 40 cycles followed by collecting signals at $60^{\circ} \mathrm{C}$ for $34 \mathrm{sec}$. SYBR melting curve analysis was performed using the RT-qPCR products, with all samples set in triplicate, and sterile deionized water was used to replace the template as a negative control. The average $\mathrm{Ct}$ value of the $\mathrm{X}$ gene and the $\beta$-actin gene of the replicate samples was obtained and the reference gene $\beta$-actin was used to correct the average $\mathrm{Ct}$ value of the genes in the untreated drug samples and treated drug samples. The calculations used were as follows: $\Delta \mathrm{Ct}$ untreated drug sample $=\mathrm{X}$ gene mean $\mathrm{Ct}$ value - $\beta$-actin gene mean $\mathrm{Ct}$ value; and $\Delta \mathrm{Ct}$ treated drug sample $=\mathrm{X}$ gene mean $\mathrm{Ct}$ value $-\beta$-actin gene mean $\mathrm{Ct}$ value. The $\Delta \mathrm{Ct}$ of the untreated drug samples and treated drug samples were normalized as follows: $\Delta \Delta \mathrm{Ct}=\Delta \mathrm{Ct}$ treated drug sample - $\Delta \mathrm{Ct}$ untreated drug sample. Finally, the difference in expression of the $\mathrm{X}$ gene between the treated and untreated drug samples was calculated as $2^{-\Delta \Delta C t}$.

Statistical analysis. Analysis of the results was performed using SPSS statistical software, version 17.0 (SPSS, Inc., Chicago, IL, USA). The values are expressed as the mean \pm standard deviation. Comparison between different groups was performed by univariate analysis of variance and pair-wise comparison using Student-Newman-Keuls method. The tests were two-sided with an $\alpha$ level of 0.05 . $\mathrm{P}<0.05$ was considered to indicate a statistically significant difference.

\section{Results}

Cell morphology. The cells in the low-dose group became round and were smaller in size with slight germination on the surface (Fig. 1A). The cells became irregular and a small number were exfoliated, floating in the culture medium. There were also a small number of cells that were swollen, ruptured and necrotic. The cells in the medium-dose group demonstrated reduced cell proliferation, decreased density and exhibited morphological changes and merging of cells 


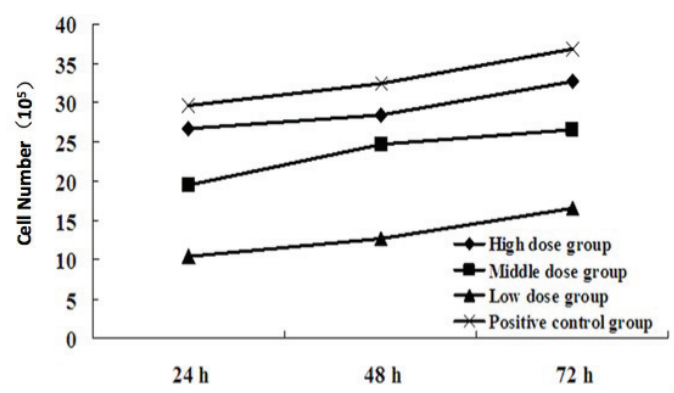

Figure 2. Inhibition of LoVo cell proliferation rate (\%) by serum from rats treated with different doses of Lingqi capsules at 24, 48 and $72 \mathrm{~h}$.



Figure 3. Effect of Lingqi capsule treatment on solid tumor weight.



Figure 4. Effect of Lingqi capsule treatment on tumor cell apoptotic rate.



Figure 5. Relative protein expression of HGF among Lingqi capsule treatment groups.

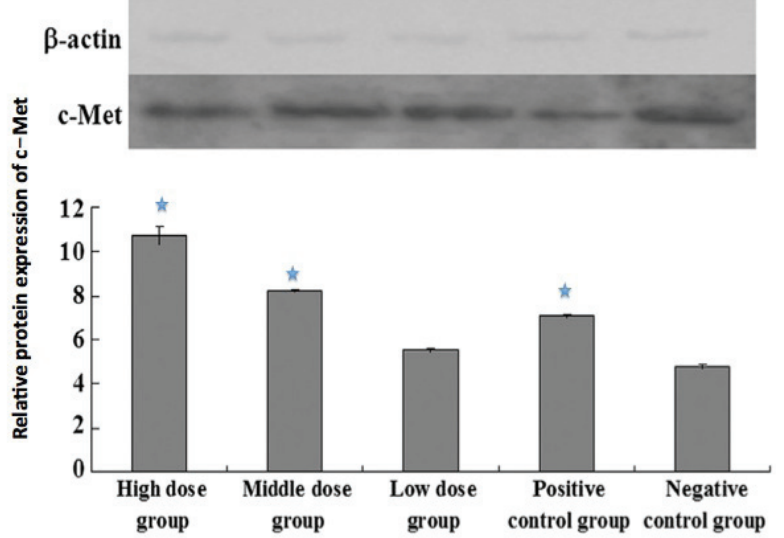

Figure 6. Relative protein expression of c-Met among the Lingqi capsule treatment groups.



Figure 7. Relative mRNA expression of HGF among Lingqi capsule treatment groups.

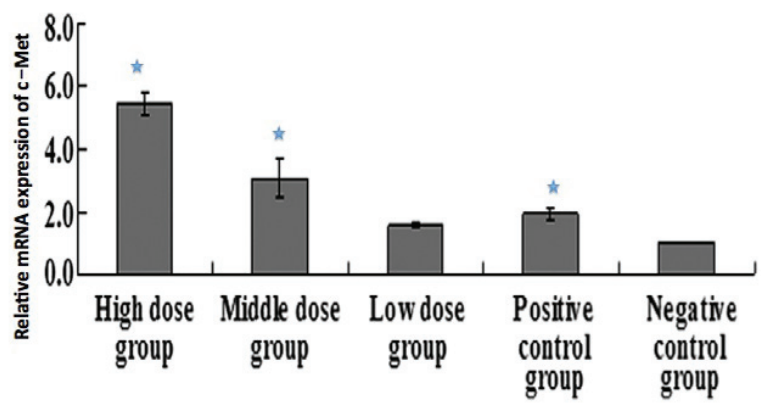

Figure 8. Relative mRNA expression of c-Met among Lingqi capsule treatment groups.

(Fig. 1B). In addition, the cells were significantly swollen, ruptured and necrotic. In the high-dose group, the cells had deeper staining, smaller volumes and became round with a condensed purple nucleus and a number of nuclei were not clearly visible (Fig. 1C). In the positive control group, the cells exhibited a lavender cytoplasm, purple oval nuclei and dark purple nucleoli (Fig. 1D). By contrast, the cells in the negative control group grew adherently with plump cytoplasms. The adjacent cells integrated into each other, grew in multi-layers, 
mainly as spindles or ovals, and exhibited rapid proliferation (Fig. 1E).

LoVo cell proliferation is inhibited by LQC serum. Following treatment with different concentrations of LQC serum (1.25, 2.5 and $5.0 \mathrm{~g} / \mathrm{kg}$ ) for 24,48 and $72 \mathrm{~h}$, proliferation of the LoVo cells was significantly inhibited (Fig. 2). Furthermore, as the serum drug concentration and prolonged exposure time was prolonged, the inhibitory effect of the LQC serum was significantly enhanced, demonstrating a time- and dose-dependent association $(\mathrm{P}<0.05)$.

LQC treatment decreases tumor size in mice. The tumor xenografts were introduced into nude mice using LoVo cells to produce tumors. Mice were treated with LQ serum and the tumor tissues were harvested to assess the effects of the treatment on tumor progression. Compared with the negative controls, tumor weights from the nude mice receiving drug treatment were significantly lower. Apoptotic rates in the highand medium-dose LQC groups and in the positive control group were significantly increased compared with those in the negative control group ( $\mathrm{P}<0.05$; Figs. 3 and 4$)$.

Protein and mRNA expression of HGF and c-Met are altered by $L Q$ treatment. The protein levels of HGF and c-Met were measured in tumors obtained from nude mice injected with LoVo cells. Compared with the negative controls, the protein expression levels of HGF in the high-, medium- and low-dose treatment groups and in the positive control group were significantly decreased, while the expression of c-Met protein was significantly increased $(\mathrm{P}<0.05$; Figs. 5 and 6$)$.

The mRNA levels of HGF and c-Met were also measured in the tumors obtained from nude mice injected with LoVo cells. Compared with the negative controls, the mRNA expression of mRNA in the high-, medium- and low-dose treatment groups and in the positive control group were significantly decreased, while the mRNA expression of c-Met was significantly increased $(\mathrm{P}<0.05)$, as shown in Figs. 7 and 8.

\section{Discussion}

In the present study, LQCs were used to treat LoVo cells as a model of colorectal cancer to investigate the inhibitory effect on tumor cells. The in vitro results demonstrated that serum from rats treated with LQCs effectively inhibited the proliferation of LoVo cells, particularly at medium and high doses, which had comparable inhibitory effects to cyclophosphamide. In addition, the inhibitory effect of LQ serum treatment was most marked after $72 \mathrm{~h}$, suggesting that LQCs have an effect on colorectal cancer cells that is enhanced with increased dosage and duration of exposure. Furthermore, in vivo experiments revealed that LQCs promote cell apoptosis, delay tumor growth and reduce tumor weight.

HGF is a pluripotent cell growth factor produced by stromal cells with a variety of biological effects (11). HGF is also a cytokine with a significant ability to stimulate liver cell regeneration through the promotion of karyokinesis, affecting motility and morphological variation in a number of epithelial cells, including those in the alveolar epithelium and gastrointestinal mucosa $(12,13)$. HGF has a variety of biological effects, which are mainly achieved through its receptor, c-Met (14). c-Met is a tyrosine-kinase receptor and is involved in the regulation of cytoskeletal rearrangement, cell proliferation, differentiation and motility $(15,16)$. Numerous studies have demonstrated that the HGF/c-Met signal transduction pathway is important in the invasion and metastasis of tumor cells and in angiogenesis $(17,18)$. Furthermore, the expression of HGF and c-Met in colorectal cancer tissues is significantly higher compared with that in benign colorectal adenoma and the normal colon tissues surrounding the tumors. In addition, the lymphatic vessel density in colorectal cancer tissues, in which HGF and c-Met expression are positive, is significantly increased. As lymph node metastasis is closely correlated with clinical stage, it is hypothesized that overexpression of HGF and c-Met can promote the occurrence and development of colorectal cancer and lymphatic metastasis (19).

In the present study, a significant reduction was observed in the protein and mRNA expression of HGF in the tumor cells of a nude mouse model of colorectal cancer treated with LQC. By contrast, the protein and mRNA expression levels of c-Met were significantly increased. The effect of a high-dose of LQC in regulating the expression of HGF and c-Met was comparable to that of cyclophosphamide, indicating that LQC may achieve its inhibitory effect on tumors through downregulating the expression of HGF and upregulating the expression of c-Met.

In conclusion, the present study demonstrated the ability of LQC to significantly inhibit the growth of LoVo cells, revealing dose-dependent activity and a significant antitumor effect in LoVo-grafted nude mice via inhibition of the HGF/c-Met signal transduction pathway. These results provide a basis for designing and selecting therapeutic regimens for colorectal cancer, drug screening and relevant investigation into the efficacy of utilizing LQC as a treatment for colorectal cancer.

\section{Acknowledgements}

The study was supported by funds from the Natural Science Foundation of Heilongjiang province (China).

\section{References}

1. Siegel R, Naishadham D and Jemal A: Cancer statistics, 2012. CA Cancer J Clin 62: 10-29, 2012.

2. Li M and Gu J: Changing patterns of colorectal cancer over the recent two decades in China. Zhonghua Wei Chang Wai Ke Za Zhi 7: 214-217, 2004 (In Chinese).

3. Bilir, C, Engin H and Temi Y V: Effect of gender on coagulation functions: a study in metastatic colorectal cancer patients treated with bevacizumab, irinotecan, 5-Fluorouracil, and leucovorin Adv Hematol 2014: 473482, 2014.

4. Yeh YC, Chen HY, Yang SH, et al: Hedyotis diffusa combined with Scutellaria barbata are the core treatment of Chinese herbal medicine used for breast cancer patients: A population-based study. Evid Based Complement Alternat Med 2014: 202378, 2014.

5. Zhao L, Zhao AG, Zhao G, et al: Survival benefit of traditional chinese herbal medicine (a herbal formula for invigorating spleen) in gastric cancer patients with peritoneal metastasis. Evid Based Complement Alternat Med 2014: 625493, 2014.

6. Xiao JY, Sun YM, Wang WK, et al: Effect of Lingqi capsule on the content of IL-6 in peripheral blood of mice bearing $\mathrm{H} 22$. China Pharmacist 10: 518-520, 2007 (In Chinese).

7. Wang HT and Su YM: Effect of Lingqi capsule on expression VEGF, MMP-2 and MMP-9 in A549 cell. Zhonghua Zhong Yi Yao Za Zhi 24: 1646-1648, 2009. (In Chinese). 
8. Li H, Wang HG, Zhao X and Su YM: The effect of Lingqi capsules on the Bcl-2 expression of apoptosis gene of A549 cell lines. Zhong Yi Yao Xin Xi 29: 105-107, 2012 (In Chinese).

9. Sankari SL, Masthan KM, Babu NA, et al: Apoptosis in cancer an update. Asian Pac J Cancer Prev 13: 4873-4878, 2012.

10. Tang JL, Zhang HH and Lai MD: Role of autophagy and apoptosis in tumor. Zhonghua Bing Li Xue Za Zhi 41: 573-576, 2012 (In Chinese).

11. Kim MD, Kim SS, Cha HY, et al: Therapeutic effect of hepatocyte growth factor-secreting mesenchymal stem cells in a rat model of liver fibrosis. Exp Mol Med 46: e110, 2014.

12. Ohya W, Funakoshi H and Nakamura T: Hepatocyte growth factor (HGF). Nihon Rinsho 63: 116-122, 2005 (In Japanese)

13. Varkaris A, Corn PG, Gaur S, et al: The role of HGF/c-Met signaling inprostate cancer progression and c-Met inhibitors in clinical trials. Expert Opin Investig Drugs 10: 1677-1684, 2011.
14. Gao CF and Vande Woude GF: HGF/SF-Met signaling in tumor progression. Cell Res 15: 49-51, 2005.

15. Faletto DL, Kaplan DR, Halverson DO, et al: Signal transduction in c-met mediated motogenesis. EXS 65: 107-130, 1993.

16. Cecchi F, Rabe DC and Bottaro DP: Targeting the HGF/Met signaling pathway in cancer therapy. Expert Opin Ther Targets 16: 553-572, 2012

17. Gao CF and Vande Woude GF: HGF/SF-Met signaling in tumor progression. Cell Res 15: 49-51, 2005.

18. Giordano S, di Renzo MF, Olivero M, et al: The C-met/HGF receptor in human tumours. Eur J Cancer Prev 1: 45-49, 1992.

19. Kataoka $\mathrm{H}$, Itoh $\mathrm{H}$, Hamasuna $\mathrm{R}$, et al: Pericellular activation of hepatocyte growthfactor/scatter factor $(\mathrm{HGF} / \mathrm{SF})$ in colorectal carcinomas: roles of HGF activator (HGFA) and HGFA inhibitor type 1 (HAI-1). Hum Cell 14: 83-93, 2001. 